\title{
ATTENUATION OF METABOLIC DYSFUNCTIONS IN THE SKELETAL MUSCLES OF TYPE 1 DIABETIC RATS BY STEVIA REBAUDIANA EXTRACTS, VIA AMPK UPREGULATION AND ANTIOXIDANT ACTIVITIES
}

\author{
Amani M. D. El-Mesallamy ${ }^{1}$, Seham A. Mahmoud ${ }^{1}$, Khalid M. Elazab², \\ Sahar A. M. Hussein ${ }^{3}$, Abdelaziz M. Hussein ${ }^{4 凶}$ \\ ${ }^{1}$ Chemistry Department, Zagazig University, Zagazig, Egypt \\ ${ }^{2}$ Biology Department, Jazan University, Jazan, Saudi Arabia \\ ${ }^{3}$ Department of Phytochemistry and Plant Systematics, National Research Center, Dokki, Egypt \\ ${ }^{4}$ Medical Physiology Department, Faculty of Medicine, Mansoura University \\ 60 Elgomhoria Str., PO 35516, Mansoura, Egypt
}

\begin{abstract}
Objectives. Stevia rebaudiana Bertoni leaves are well-known for their sweetness and have been used as a non-caloric sweetener in several countries. It has numerous therapeutic properties which have been proven safe and effective over hundreds of years. In the present study, we aimed to evaluate the possible antioxidant effects of stevia extracts and their role in regulating AMPK in type-1 diabetic rats.

Methods. Fifty male Sprague Dawely rats were divided into: (1) normal control (NC) group; normal rats receiving $0.5 \mathrm{ml}$ normal saline, (2) DM group; diabetic rats receiving $0.5 \mathrm{ml}$ normal saline, (3) DM + MSE group; DM rats receiving $200 \mathrm{mg} / \mathrm{kg}$ of methanolic extract of stevia, (4) DM + S group; DM rats receiving $2 \mathrm{mg} / \mathrm{kg}$ of pure stevioside, and (5) DM + CGA group; DM rats receiving $10 \mathrm{mg} / \mathrm{kg}$ of pure chlorogenic acid. Four weeks after treatment, AMPK activity, GLUT4 mRNA and oxidative stress markers were measured in frozen muscles. Also, fasting blood glucose in serum, insulin and HbAlc were measured at the end of experiment.

Results. DM caused a significant increase in serum fasting glucose, HbA1c and muscle MDA with significant reduction in serum insulin, muscle SOD, catalase, GPx, AMPK activity and GLUT4 expression $(p<0.05)$. Treatment with stevia extract, pure stevioside and chlorogenic acid caused significant improvements in the studied parameters $(p<0.05)$.

Conclusions. We concluded that stevia extracts and derivatives may improve metabolic dysfunction in skeletal muscles via upregulation of AMPK and GLUT4 and suppression of oxidative stress.
\end{abstract}

Keywords: type-1 diabetes, stevia leaf extracts, AMPK, antioxidant

\section{INTRODUCTION}

Diabetes mellitus (DM) is a systemic metabolic disease, the incidence of which is increasing at an exponential rate around the world. Although type 2
DM (T2DM) accounts for around $90 \%$ of all diabetes patients, type $1 \mathrm{DM}$ (T1DM) is also on the increase (Laron et al., 2015). The hallmark of DM is 
hyperglycemia, which results from the disruption of glycemic control due to the lack of insulin secretion from pancreatic beta cells, or the impairment of insulin action (Thomas and Philipson, 2015). The generation of reactive oxygen species (ROS) secondary to hyperglycemia is enhanced in diabetes, as evidenced by significant elevation in the products of lipid peroxidation, such as 4-hydroxy-2-nonenal (4-HNE) or malondialdehyde (MDA) (Sahin et al., 2012; Sies, 1997). Oxidative stress plays an important role in the pathogenesis of diabetes complications due to glucose autoxidation and glycation of proteins, which depletes the antioxidant defense system and thus promotes free radical generation (Sahin et al., 2012; Sies, 1997). Recently, much attention has been focused on dietary natural antioxidants capable of inhibiting reactive oxygen radical-mediated oxidative stress (Ghanta et al., 2007). Diabetic complications affecting skeletal muscles include contractile weakness, changes in muscle fibre type, reduction in oxidative activity and peripheral insulin resistance (Petersen and Shulman, 2002). Muscle is the most important organ in which glucose uptake is insulindependent (Wasserman, 2009); therefore, impaired hormonal signaling has a deleterious effect on muscle glucose uptake. Also, in skeletal muscles, the activation of both insulin and AMPK stimulates glucose uptake by enhancing GLUT4 translocation to the cell plasma membrane (Do et al., 2012). When activated, AMPK phosphorylates many downstream targets that lead to the inhibition of pathways that consume energy, such as fatty acid synthesis, cholesterol synthesis, and gluconeogenesis (Alcantara-Aragon et al., 2015). This downstream phosphorylation also leads to the stimulation of pathways that generate energy, glucose uptake, fatty acid oxidation and glycolysis (Alcantara-Aragon et al., 2015). Activation of AMPK requires both an increase in the intracellular AMP : ATP ratio and phosphorylation of Thr172 on the "activation loop" of the $\alpha$-subunit (Birnbaum, 2005). Physiological activators of AMPK are thought to be exercise and calorie restriction, as they help to increase the cellular ratio of AMP : ATP (Chen et al., 2003). Also, a polyphenol derived from plants which are used in traditional Asian medicines are thought to activate AMPK (Hawley et al., 2010). Stevia rebaudiana Bertoni is a small perennial shrub that belongs to the aster family. It grows primarily in the Amambay mountain range of Paraguay (Mizutani and Tanaka, 2002). Steviol glycosides (SGs) are found in the leaves of a scrub plant native to the subtropical regions of South America. In South America, Stevia rebaudiana Bertoni extract has been used for centuries as a sweetening food additive in South America (Geuns, 2003). Six steviol glycosides (stevioside, steviolbioside, rebaudioside A, B, C and dulcoside) can be detected in stevia leaves (Geuns, 2003). Non-caloric sweeteners are increasingly introduced into common foods as a sugar replacement, and are for this reason recommended for weight loss and for individuals suffering from glucose intolerance and diabetes (DuBois and Prakash, 2012). We hypothesized that stevia could activate AMPK, and thereby improve metabolic dysfunctions and Glut4 upregulation in skeletal muscles in diabetic rats. Therefore, our study was designed to investigate the role of stevia leaf extract and its derivatives (stevioside and chlorogenic acid) as anti-diabetic and antioxidant agents, as well as their effects on the expressions of a AMP-activated protein kinase (AMPK) involved in the translocation of GLUT 4.

\section{MATERIALS AND METHODS}

\section{Extraction and purification}

Stevia plant leaves (S. rebaudiana Bertoni) were obtained from the Stevia International Company for Agro-industry Product (SICAP), Cairo, Egypt. Procedures for extraction and isolation were performed to produce methanolic stevia extract, isolation and purification two natural steviosides from $S$. rebaudiana leaves were done according to El-Mousalamy et al. (2017).

\section{Experimental animals}

A total of adult fifty male Sprague Dawely rats, weighing 180-210 g were obtained and housed in a controlled environment that was maintained under a 12-hour light $\backslash$ dark cycle and a temperature of $25^{\circ} \mathrm{C}$ $\left( \pm 3^{\circ} \mathrm{C}\right)$ at the Medical Experimental Research Centre (MERC), Mansoura university. Rats were housed individually in separate cages and fed on normal standard rat chow, with free access to water. All procedures were approved by our local IRB-committee (\# r.17.12.275). 


\section{Type 1 DM animal model}

Induction of type $1 \mathrm{DM}$ was achieved by a single intraperitoneal (i.p.) dose of streptozotocin (STZ) $(50 \mathrm{mg} / \mathrm{kg}$ b.w.) as previously described by our research group (El-Mousalamy et al., 2017). The onset of DM was confirmed by the measurement of fasting blood glucose level one week after STZ administration. Rats with a blood glucose level of more than $300 \mathrm{mg} / \mathrm{dl}$ were included in the study (Muranyi et al., 2006).

\section{Study design}

The rats were segregated randomly into 5 groups of 10 rats, as follows:

1. Normal control (NC) group: normal rats receiving $0.5 \mathrm{ml}$ normal saline by mouth by gastric gavage once daily for 4 weeks.

2. Diabetes mellitus (DM) group: diabetic rats receiving $0.5 \mathrm{ml}$ normal saline by mouth by gastric gavage once daily for 4 weeks.

3. DM + methanolic stevia extract (MSE) group: diabetic rats receiving $0.5 \mathrm{ml}$ normal saline containing $200 \mathrm{mg} / \mathrm{kg}$ b.w. methanolic extract of stevia leaves, by mouth, by gastric gavage once daily for 4 weeks (El-Mousalamy et al., 2017).

4. DM + stevioside (S) group: diabetic rats receiving $0.5 \mathrm{ml}$ normal saline containing $2 \mathrm{mg} / \mathrm{kg}$ b.w. of pure stevioside, by mouth, by gastric gavage once daily for 4 weeks (El-Mousalamy et al., 2017).

5. DM + chlorogenic acid (CGA) group: diabetic rats receiving $0.5 \mathrm{ml}$ normal saline containing $10 \mathrm{mg} / \mathrm{kg}$ b.w. of pure chlorogenic acid, by mouth, by gastric gavage once daily for 4 weeks (El-Mousalamy et al., 2017).

\section{Collection of blood samples and harvesting soleus muscle specimens}

At the end of experiment, the rats were euthanized by $\mathrm{Na}^{+}$thiopental (at high dose; $120 \mathrm{mg} / \mathrm{kg}$ i.p.) and blood samples were withdrawn by heart puncture. After centrifugation of the blood samples, the sera were stored at $-20^{\circ} \mathrm{C}$ until the time of biochemical analysis. Also, the soleus muscles on both sides were rapidly and carefully dissected from the surrounding fasciae and broken into small cubes (about $30 \mathrm{~g}$ ), placed in RNAse free cryotubes and stored in liquid nitrogen for PCR and biochemical analysis.

\section{Measurement of serum parameters}

Serum fasting blood glucose and $\mathrm{HbAlc}$ were measured by commercially available kits, according to manufacturer instructions (Cat \#,10121 \& Cat \#,10657 Human Diagnostics, Germany). Also, fasting serum insulin levels were determined by a competitive assay method with an enzyme-linked immunosorbent assay (ELISA) using a commercially available kit (Cat \# K4271-100, BioVision's, USA). HOMA-insulin resistance index was calculated from the formula of Matthews et al. (1985) as follows:

HOMA-IR $=\frac{\begin{array}{c}\text { fasting insulin level, } \mu \mathrm{U} / \mathrm{ml} \times \\ \times \text { fasting glucose level, } \mathrm{mmol} / \mathrm{L}\end{array}}{22.5}=\mathrm{mmol} \cdot \mu \mathrm{U} / \mathrm{L}^{2}$

\section{Measurement of oxidative stress biomarkers in soleus muscle}

The tissue was homogenized with ice-cold phosphatebuffered saline (PBS; $0.01 \mathrm{M}, \mathrm{pH}=7.4$ ) to remove excess hemolysis blood, then ground into small pieces to be homogenized in PBS (9 mL PBS would be appropriate for $1 \mathrm{~g}$ of tissue). It is recommended to add some protease inhibitor into the PBS with a glass homogenizer on ice. The homogenates are then centrifuged for 5 minutes at $5000 \times \mathrm{g}$ to retrieve the supernatant. Muscle MDA concentration was measured spectrophotometrically at $532 \mathrm{~nm}$ by the method of Ohakawa et al. (1979), while the activity of glutathione peroxidase (GSH-Px) was measured spectrophotometrically at $412 \mathrm{~nm}$, according to Lawrence and Burk (1976). SOD activity in soleus muscle was also assessed by spectrophotometer at $505 \mathrm{~nm}$ according to McCord and Fridovich (1969), while catalase (CAT) activity was measured using hydrogen peroxide $\left(\mathrm{H}_{2} \mathrm{O}_{2}\right)$ as a substrate (Aebi, 1974). The disappearance of $\mathrm{H}_{2} \mathrm{O}_{2}$ was observed at $240 \mathrm{~nm}$.

\section{Measurement of AMPK activity in tissue homogenates}

The activity of AMPK was measured in soleus muscle homogenates using BioVision's AMPK ELISA kit (Cat \# E4280-100). All steps of the assay were done according to manufacturer instructions at a wave length of $450 \mathrm{~nm}$. The detection range for this kit is $0.313-20 \mathrm{ng} / \mathrm{ml}$. 


\section{Measurement of mRNA of GLUT4 by real time PCR}

Details of the procedures, kits and the sequences of primers of the studied gene (GLUT4) and control gene $(\beta$ actin) are described in detail in our previous work (El-Mousalamy et al., 2017).

\section{Statistical analysis}

All statistical analyses were done using SPSS (version 16.0). Data is presented as mean \pm standard deviation (SD). One-way ANOVA with Scheffe's post-hoc test was carried out. Statistical significance was considered to be $p \leq 0.05$.

\section{RESULTS}

Effects of methanolic stevia extracts, stevioside and CGA on body weight, fasting blood glucose, fasting serum insulin, HOMA-IR and HbA1c

By the end of experiment, body weight was significantly higher in the $\mathrm{NC}$ group than the DM, $\mathrm{DM}+\mathrm{MSE}$ and $\mathrm{DM}+\mathrm{S}$ groups $(p<0.05)$. Also, the DM + CGA group showed significant increase in body weight than DM and DM + MSE groups did $(p<0.05$; Table 1$)$.

Regarding fasting blood glucose level, it was significantly higher in the DM group than the $\mathrm{NC}$ group $(p<0.005)$, while its level was significantly lower in all treated groups (DM + MSE, DM + S and DM + CGA) than the DM group $(p<0.05)$. Also, the DM + MSE and $\mathrm{DM}+\mathrm{S}$ groups showed a more significant reduction in fasting blood glucose than did the DM + CGA group ( $p<0.05$; Table 1$)$.

Fasting insulin in the serum was also significantly lower in the DM group than the NC group $(p<0.05)$. On the other hand, it was significantly higher in the $\mathrm{DM}+\mathrm{SE}, \mathrm{DM}+\mathrm{S}, \mathrm{DM}+\mathrm{CGA}$ groups than the DM group $(p<0.05)$, with the highest significant elevation noticed in the DM + CGA group (Table 1). HOMA-IR index showed a significant increase in the $\mathrm{DM}, \mathrm{DM}+\mathrm{MSE}, \mathrm{DM}+\mathrm{S}$ and $\mathrm{DM}+$ CGA groups compared to the NC group $(p<0.05)$. Also, HOMA-IR was significantly higher in the DM + MSE group than other studied groups $(\mathrm{DM}, \mathrm{DM}+\mathrm{S}$ and $\mathrm{DM}+\mathrm{CGA})(p<0.05$; Table 1). Moreover, HbA1c levels were significantly higher in the DM group than the NC group $(p<0.005)$, but were significantly lower in all treated groups (DM + MSE, DM $+\mathrm{S}$ and DM + CGA) than the DM group $(p<0.05)$. Also, the DM + MSE and DM $+\mathrm{S}$ groups showed a more significant reduction in $\mathrm{HbAlc}$ than did the $\mathrm{DM}+\mathrm{S}$ group $(p<0.05$; Table 1$)$.

\section{Effects of methanolic stevia extracts, stevioside and CGA on markers of oxidative stress}

The activities of GPx, SOD and catalase in soleus muscle were significantly lower in the DM group than the NC group $(P<0.05)$, and their activities significantly increased in the treated groups (DM $+\mathrm{MSE}, \mathrm{DM}+\mathrm{S}$, $\mathrm{DM}+\mathrm{CGA})$ compared to the DM group $(P<0.05)$.

Table 1. Body weight, FBS, insulin, HOMA-IR and HBA1c in different groups

\begin{tabular}{lccccc}
\hline \multicolumn{1}{c}{ Groups } & $\begin{array}{c}\mathrm{NC} \\
(n=6)\end{array}$ & $\begin{array}{c}\mathrm{DM} \\
(n=6)\end{array}$ & $\begin{array}{c}\mathrm{DM}+\mathrm{MSE} \\
(n=6)\end{array}$ & $\begin{array}{c}\mathrm{DM}+\mathrm{S} \\
(n=6)\end{array}$ & $\begin{array}{c}\text { DM + CGA } \\
(n=6)\end{array}$ \\
\hline Weight, g & $191.67 \pm 5.854$ & $170.83 \pm 4.491^{*}$ & $165.66 \pm 4.45^{*}$ & $177.00 \pm 5.32^{*}$ & $182.16 \pm 3.97^{\#}$ \\
FBS, mg/dl & $85.83 \pm 8.89$ & $370.50 \pm 19.96^{*}$ & $238.77 \pm 19.38^{* \#}$ & $285.43 \pm 16.79^{* * \$}$ & $188.67 \pm 10.65^{* \# \$}$ \\
Insulin, mIU/L & $15.10 \pm 0.77$ & $5.78 \pm 0.78^{*}$ & $11.65 \pm 1.90^{* \#}$ & $8.32 \pm 0.33^{* * \$}$ & $12.58 \pm 1.69^{* \#+}$ \\
HOMA-IR & $3.20 \pm 0.40$ & $5.27 \pm 0.58^{*}$ & $6.93 \pm 1.47^{*}$ & $5.38 \pm 0.76^{*}$ & $5.51 \pm 1.65^{*}$ \\
HBA1c, \% & $4.68 \pm 0.23$ & $16.95 \pm 3.40^{*}$ & $9.35 \pm 1.51^{* \#}$ & $9.65 \pm 0.46^{* \#}$ & $7.07 \pm 0.43^{* *}$ \\
\hline
\end{tabular}

All data were expressed as mean \pm SD. One-way ANOVA with Scheffe's posthoc test. NC - normal control, DM - diabetes mellitus, MSE - methanolic stevia extract, S - stevioside, CGA - chlorogenic acid, FBS - fasting blood sugar. *Significant vs NC group, ${ }^{*}$ significant vs DM group, ${ }^{\$}$ significant vs DM + MSE group, ${ }^{*}$ significant vs DM $+\mathrm{S}$ group. 
No significant difference was observed in their activity between the DM + CGA and DM + MSE groups $(P>0.05$; Fig. 1-3). Compared to the NC group, the $\mathrm{DM}, \mathrm{DM}+\mathrm{MSE}, \mathrm{DM}+\mathrm{S}$ and DM + CGA groups showed significantly higher levels of lipid peroxidation products (MDA) in the soleus muscle $(P<0.05)$. Also, the treated $(\mathrm{DM}+\mathrm{MSE}, \mathrm{DM}+\mathrm{S}$ and $\mathrm{DM}+\mathrm{CGA})$ groups showed significant reductions in MDA levels compared to the DM group $(P<0.05$; Fig. 4$)$.

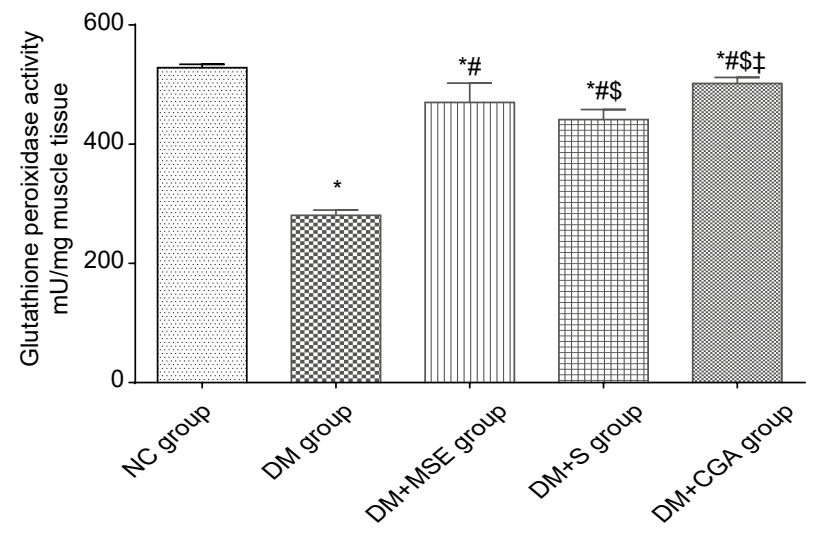

Fig. 1. Soleus muscle glutathione peroxidase activity in different groups, $\mathrm{mU} / \mathrm{mg}$ muscle tissue: $*$ - significant vs $\mathrm{NC}$ group, \# - significant vs DM group, \$ - significant vs DM + MSE group, +- significant vs DM $+\mathrm{S}$ group

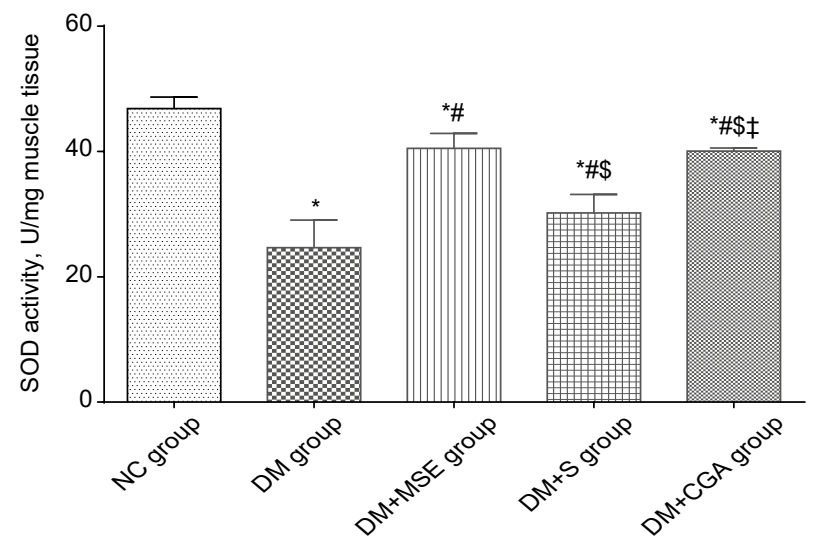

Fig. 2. Soleus muscle superoxide dismutase activity in different groups, U/mg muscle tissue: $*$ - significant vs NC group, $\#-$ significant vs DM group, $\$$ - significant vs DM + MSE group, $\$-$ significant vs DM $+\mathrm{S}$ group

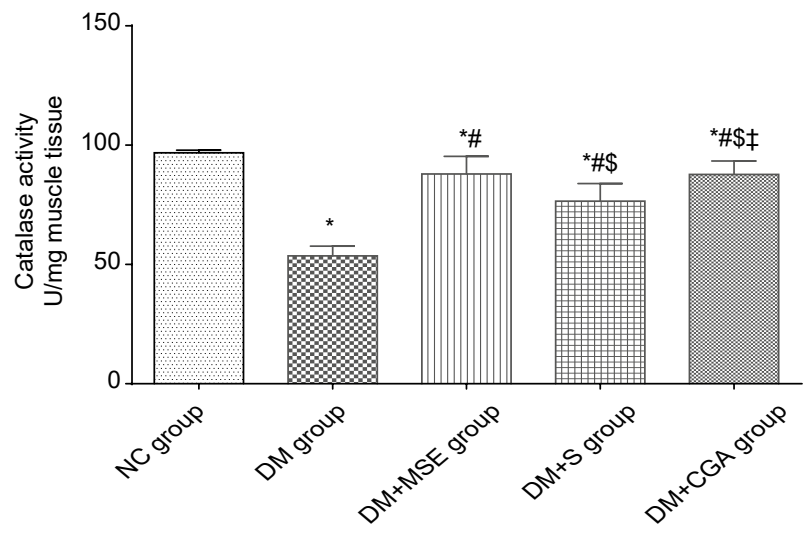

Fig. 3. Soleus muscle catalase activity in different groups, U/g muscle tissue: $*$ - significant vs NC group, \# - significant vs DM group, \$ - significant vs DM + MSE group, +- significant vs DM + S group

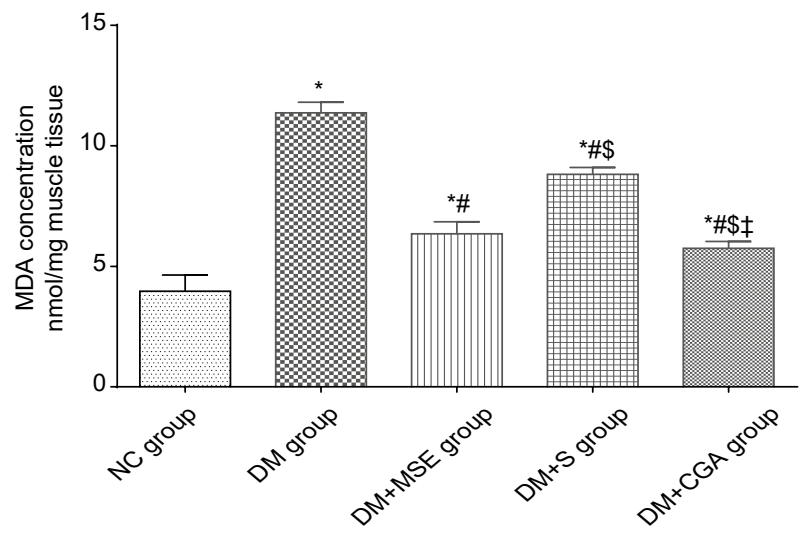

Fig. 4. Soleus muscle MDA in different groups, $\mathrm{nmol} / \mathrm{g}$ muscle tissue: $*$ - significant vs NC group, $\#-$ significant vs DM group, $\$$ - significant vs DM + MSE group, $\$-$ significant vs DM $+\mathrm{S}$ group

\section{Effects of methanolic stevia extracts, stevioside and CGA on expression of GLUT4 gene}

The DM group showed a significant reduction in GLUT4 mRNA expression compared to the NC group $(p<0.05)$, while the treated groups (DM + MSE, $\mathrm{DM}+\mathrm{S}$ and $\mathrm{DM}+\mathrm{CGA}$ ) showed a significant increase in GLUT4 expression compared to the DM group $(p<0.05)$. Moreover, the DM + CGA group showed significantly higher levels of GLUT 4 mRNA than did the DM + MSE and DM $+\mathrm{S}$ groups ( $p<0.05$; Fig. 5$)$. 


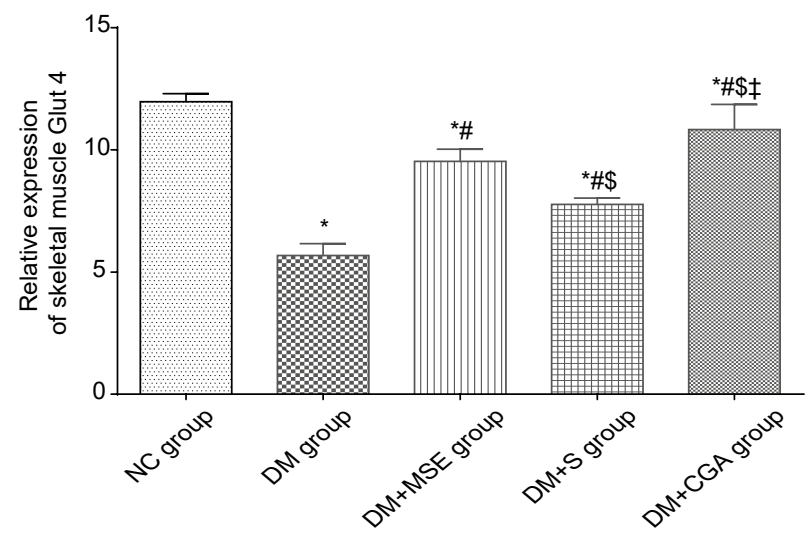

Fig. 5. Relative expression of mRNA of GLUT4 in soleus muscle in different groups: $*-$ significant vs NC group, \# - significant vs DM group, $\$$ - significant vs DM + MSE group, $\$-$ significant vs DM $+\mathrm{S}$ group

\section{Effects of methanolic stevia extracts, stevioside and CGA on activity of AMPK}

The DM group showed a significant reduction in AMPK activity compared to the NC group $(p<0.05)$, while the treated groups $(\mathrm{DM}+\mathrm{MSE}, \mathrm{DM}+\mathrm{S}$ and $\mathrm{DM}+\mathrm{CGA}$ ) showed a significant increase in AMPK activity compared to the DM group $(p<0.05)$. Moreover, the CGA group showed a significant increase in AMPK activity compared to the DM + MSE and $\mathrm{DM}+\mathrm{S}$ groups $(p<0.05$; Fig. 6$)$.

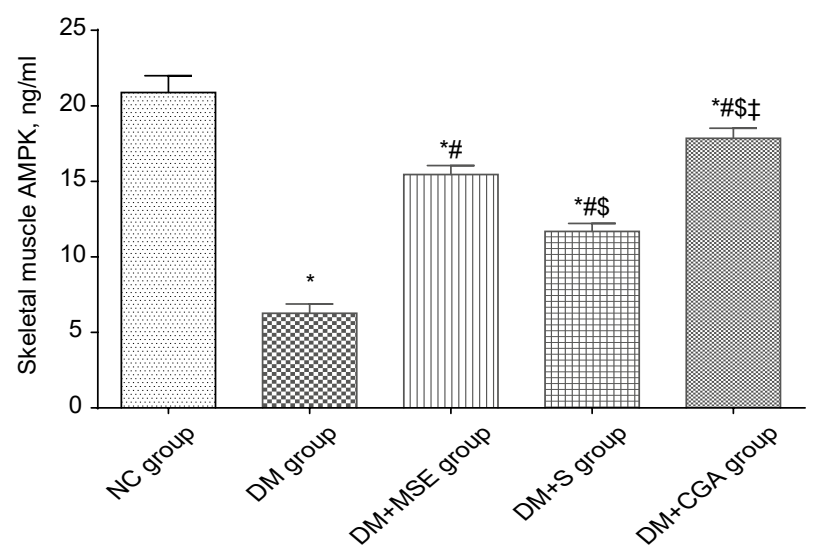

Fig. 6. AMPK activity in soleus muscle in different groups, ng/mg muscle tissue: $*$ - significant vs NC group, \#- significant vs DM group, \$ - significant vs DM + MSE group, $\ddagger$-significant vs DM $+\mathrm{S}$ group

\section{DISCUSSION}

Type $1 \mathrm{DM}$ is characterized by hyperglycemia and hyperlipidemia, with low insulin levels (Guo, 2014; Ford and Liu, 2001). As demonstrated by previous studies, the present study showed that streptozotocin (STZ) injection, at a dose of $50 \mathrm{mg} / \mathrm{kg}$ b.w., caused a significant elevation in fasting blood sugar and a significant reduction in fasting insulin. Moreover, treatment with stevia extracts, stevioside and CGA caused significant improvements in fasting blood glucose and insulin, with the most significant improvement found after CGA treatment. These findings suggest that CGA, stevioside and stevia extracts have anti-diabetic effects, in line with previous studies that have reported hypoglycemic effects for stevia extracts and derivatives. Previous studies have reported that stevia extracts have hypoglycemic effects in experimental animal models of DM (Assaei et al., 2016; Das et al., 2000; Misra et al., 2011). Also, Karthikesan et al. (2010) demonstrated that CGA at a dose of $5 \mathrm{mg} / \mathrm{kg}$ b.w. exerts anti-diabetic potential in STZ (45 $\mathrm{mg} / \mathrm{kg}$ b.w.) nicotinamide-induced diabetic rats, while Jeppesen et al. (2000) documented stevioside and steviol as potent antihyperglycemic agents. These hypoglycemic effects of the stevia extract and its derivatives may be due to its central effects by enhancing insulin secretion (as evidenced by significant elevation in fasting insulin in the animal groups treated with these agents), or due to its peripheral action, improving insulin sensitivity (as evidenced by the significant elevation in GLUT4 expression in the muscle).

GLUT4, which is an insulin-dependent glucose transporter muscle, exerts its function by translocating to the plasma membrane from intracellular stores in response to insulin (Watson and Pessin, 2006) and also in response to muscle contraction (Lauritzen and Schertzer, 2010), allowing the entry of glucose into muscle cells. Changes in GLUT4 expression are observed in physiological states of altered glucose homeostasis. In the present study, we found that the expression of mRNA of GLUT4 was down regulated in type $1 \mathrm{DM}$. Moreover, the present study demonstrated that treatment with stevia extract and stevioside and CGA upregulated the expression of GLUT4 in skeletal muscle, which enhanced glucose uptake and explains its hypoglycemic effects in DM. Previous studies 
suggested that steviol glycosides could act by modulating GLUT translocation through the PI3K/Akt pathway, since treatments with both insulin and Stevia extracts increased the phosphorylation of PI3K and Akt (Rizzo et al., 2013). Furthermore, Stevia extracts were able to reverse the effects of the reduction of glucose uptake caused by methyl glyoxal, an inhibitor of the insulin receptor/PI3K/Akt pathway (Ong et al., 2012; Rizzo et al., 2013), which demonstrated for the first time that CGA stimulates glucose transport in skeletal muscle via the activation of AMPK.

In this study, we demonstrated that stevia extract treatment showed significant induction of Glut 4 and its translocation to the plasma membrane via activating AMPK. Furthermore, this data demonstrates that stevia extract, stevioside and CGA act as insulin actionstimulated glucose transport in skeletal muscle via the GLUT 4 translocation, mediated by the activation of AMPK, compared to non-treated diabetic or insulintreated groups. These findings are in agreement with Prata et al. (2017), who suggested that steviol glycosides caused an increase in glucose uptake into rat fibroblasts by activating the PI3K/Akt pathway, thus inducing Glut4 translocation to the plasma membrane, and also with Ong et al. (2012), who found that CGA stimulated and enhanced both basal and insulin-mediated 2DG transports in soleus muscle. In L6 myotubes, CGA caused a dose- and time-dependent increase in glucose transport. Compound $\mathrm{c}$ and AMPK $\alpha 1 / 2$ siRNA abrogated the CGA-stimulated glucose transport. Consistently with these results, CGA was found to phosphorylate AMPK and ACC, which is compatible with increased AMPK activities.

It is well known that the permanent hyperglycemia characterizing diabetes causes glucose autoxidation and glycation of proteins (Wolff and Dean, 1987), which thereby depletes the antioxidant defense system, thus promoting free radical generation. In addition, the activity of SOD and CAT antioxidant enzymes and GSH levels are significantly reduced in diabetic animals (Shivanna et al., 2013). In agreement with these results, we demonstrated a significant reduction in the activities of SID, CAT and GPx in the present study, with a significant increase in lipid peroxidation marker (MDA). Also, many authors have reported the direct antioxidant activity of extracts from the leaves of Stevia rebaudiana Bertoni, owing to the presence of alkaloids, flavonoids, and polyphenols (Ruiz-Ruiz et al., 2017). In the present study, we demonstrated that Stevia extract, stevioside and chlorogenic acid caused a significant increase in the activities of SOD, CAT and Gpx, together with a significant reduction in lipid peroxidation (MDA) in soleus muscle. Also, Shivanna et al. (2013), showed that feeding of rats with the whole stevia leaf powder and extracted polyphenols reduced the MDA concentration in the liver and improved its antioxidant status through antioxidant enzymes. Also, previous studies have demonstrated the free radical scavenging and antioxidant activity of chlorogenic acid in vitro (Xiang and Ning, 2008). Kim et al. (2012) suggested that chlorogenic acid prevented chemically-induced damage in the liver and primary cortical neurons by reducing oxidative damage and apoptosis.

Our data findings, combined with evidence from other studies regarding the insulin-mimetic effects and antioxidant properties exerted by steviol glycosides, suggest their potential beneficial role in the co-treatment of diabetes and health maintenance (Prata et al., 2017).

\section{CONCLUSIONS}

We concluded that stevia extracts, stevioside and chlorogenic acid might improve the metabolic dysfunctions of skeletal muscles in type 1 diabetes via upregulation of GLUT4 and AMPK activity, as well as via suppression of oxidative stress and enhancing the endogenous antioxidants in muscles such as SOD, CAT and GPx enzymes.

\section{REFERENCES}

Aebi, H. (1974). Catalase. In: H. U. Bergmeyer (Ed.), Methods of enzymatic analysis (pp. 673-684). New York: Academic Press. http://dx.doi.org/10.1016/b978-0-12-0913 02-2.50032-3

Alcantara-Aragon, V., Gonzalez, C., Corcoy, R., Ubeda, J., Chico, A. (2015). Carbohydrate-to-insulin ratio in a Mediterranean population of type 1 diabetic patients on continuous subcutaneous insulin infusion therapy. J. Diab. Sci. Technol., 9(3), 588-592. http://dx.doi.org/ $10.1177 / 1932296814563571$

Assaei, R., Mokarram, P., Dastghaib, S., Darbandi, S., Darbandi, M., Zal, F., ..., Ranjbar Omrani, G. H. (2016). Hypoglycemic effect of aquatic extract of stevia in pancreas 
El-Mesallamy, A. M. D., Mahmoud, S. A., Elazab, K. M., Hussein, S. A. M., Hussein, A. M. (2018). Attenuation of metabolic dysfunctions in the skeletal muscles of type 1 diabetic rats by Stevia rebaudiana extracts, via AMPK upregulation and antioxidant activities. Acta Sci. Pol. Technol. Aliment., 17(3), 289-297. http://dx.doi.org/10.17306/J.AFS.2018.0567

of diabetic rats: PPAR $\gamma$-dependent regulation or antioxidant potential. Avic. J. Med. Biotechnol., 8(2), 65-74.

Birnbaum, M. J. (2005). Activating AMP-activated protein kinase without AMP. Mol. Cell., 19(3), 289-90. http:// dx.doi.org/10.1016/j.molcel.2005.07.012

Chen, Z. P., Stephens, T. J., Murthy, S., Canny, B. J., Hargreaves, M., Witters, L. A., Kemp, B. E., McConell, G. K. (2003). Effect of exercise intensity on skeletal muscle AMPK signaling in humans. Diabetes, 52, 2205-2212. http://dx.doi.org/10.2337/diabetes.52.9.2205

Das, S., Vasisht, S., Snehalta, Das, N., Shrivastava, M. (2000). Correlation between total antioxidant status and lipid peroxidation in hypercholesterolemia. Curr. Sci., $78(4), 486$.

Do, G. M., Jung, U. J., Park, H. J., Kwon, E. Y., Jeon, S. M., McGregor, R. A., Choi, M. S. (2012). Resveratrol ameliorates diabetes-related metabolic changes via activation of AMP-activated protein kinase and its downstream targets in $d b / d b$ mice. Mol. Nutr. Food Res., 56, 1282-1291. http://dx.doi.org/10.1002/mnfr.201200067

DuBois, G. E., Prakash, I. (2012). Non-caloric sweeteners, sweetness modulators, and sweetener enhancers. Ann. Rev. Food Sci. Technol., 3, 353-380. http://dx.doi. org/10.1146/annurev-food-022811-101236

El-Mousalamy, A. M. D., Hussein, A. M., Mahmoud, S. A., ElAzab, Kh. M. (2017). Modulation of metabolic and contractile dysfunctions of soleus muscle in type 1 diabetic rats by Stevia rebaudiana Bert. extracts and some of its derivatives: Comparative experimental study. IJSER, 8(9), 1543-1566.

Ford, E. S., Liu, S. (2001). Glycemic index and serum highdensity lipoprotein cholesterol concentration among US adults. Arch. Inter. Med., 161(4), 572-576. http://dx.doi. org/10.1001/archinte.161.4.572

Geuns, J. (2003). Stevioside. Phytochemistry, 64, 913-921. http://dx.doi.org/10.1016/S0031-9422(03)00426-6

Ghanta, S., Banerjee, A., Poddar, A., Chattopadhyay, S. (2007). Oxidative DNA damage preventive activity and antioxidant potential of Stevia rebaudiana (Bertoni), a natural sweetener. J. Agric. Food Chem., 55, 1096210967. http://dx.doi.org/10.1021/jf071892q

Guo, S. (2014). Insulin signaling, resistance, and the metabolic syndrome: Insights from mouse models to disease mechanisms. J. Endocrinol., 220(2), T1-T23. http:// dx.doi.org/10.1530/JOE-13-0327

Hawley, S. A., Ross, F. A., Chevtzoff, C., Green, K. A., Evans, A., Fogarty, S., ..., Hardie, D. G.(2010). Use of cells expressing gamma subunit variants to identify diverse mechanisms of AMPK activation. Cell Metab., 11(6), 554-565. http://dx.doi.org/10.1016/j.cmet.2010.04.001
Jeppesen, P. B., Gregersen, S., Poulsen, C. R., Hermansen, K. (2000). Stevioside acts directly on pancreatic $\beta$-cells to secrete insulin; Actions independent of cyclic adenosine monophosphate and adenosine triphosphate-sensitive $\mathrm{K}^{+}$-channel activity. Metabolism, 49(2), 208-214. http://dx.doi.org/10.1016/S0026-0495(00)91325-8

Karthikesan, K., Pari, L., Menon, V. P. (2010). Combined treatment of tetra hydro curcumin and chlorogenic acid exerts potential antihyperglycemic effect on streptozotocin-nicotinamide induced diabetic rats. Gen. Physiol. Biophys., 29(1), 23-30. http://dx.doi.org/10.4149/ gpb_2010_01_23

Kim, J., Lee, S., Shim, J., Kim, H. W., Kim, J., Jang, Y. J., ..., Lee, H. J. (2012). Caffeinated coffee, decaffeinated coffee, and the phenolic phytochemical chlorogenic acid up-regulate NQO1 expression and prevent $\mathrm{H}_{2} \mathrm{O}_{2}$ -induced apoptosis in primary cortical neurons. Neurochem Int., 60, 466-474. http://dx.doi.org/10.1016/j. neuint.2012.02.004

Laron, Z., Hampe, C. S., Shulman, L. M. (2015). The urgent need to prevent type 1 autoimmune childhood diabetes. Pediatr. Endocrinol. Rev., 12, 266-282.

Lauritzen, H. P., Schertzer, J. D. (2010). Measuring GLUT4 translocation in mature muscle fibers. Am. J. Physiol. Endocrinol. Metab., 299, E169-E179. http://dx.doi. org/10.1152/ajpendo.00066.2010

Lawrence, R. A., Burk, R. F. (1976). Glutathione peroxidase activity in selenium-deficient rat liver. Biochem. Biophys. Res. Commun., 71, 952-958. http://dx.doi. org/10.1016/0006-291X(76)90747-6

Muranyi, M., Ding, Ch., He, Q.-P., Lin, Y., Li, P.-A. (2006). Streptozotocin induced diabetes causes astrocyte death after ischemia and reperfusion injury. Diabetes, 55, 349-355. http://dx.doi.org/10.2337/diabetes.55.02.06. db05-0654

Matthews, D. R., Hosker, J. P., Rudenski, A. S., Naylor, B. A., Treacher, D. F., Turner, R. C. (1985). Homeostasis model assessment: insulin resistance and b-cell function from fasting plasma glucose and insulin concentrations in man. Diabetologia, 28(7), 412-419.

McCord, J. M., Fridovich, I. (1969). Superoxide dismutase: an enzymic function for erythrocuprein (hemocuprein). J. Biol. Chem., 244, 6049-6055.

Misra, H., Soni, M., Silawat, N., Mehta, D., Mehta, B. K., Jain, D. C. (2011). Antidiabetic activity of medium-polar extract from the leaves of Stevia rebaudiana Bert. (Bertoni) on alloxan-induced diabetic rats. J. Pharm. Bioallied. Sci., 3(2), 242-248. http://dx.doi. org/10.4103/0975-7406.80779 
El-Mesallamy, A. M. D., Mahmoud, S. A., Elazab, K. M., Hussein, S. A. M., Hussein, A. M. (2018). Attenuation of metabolic dysfunctions in the skeletal muscles of type 1 diabetic rats by Stevia rebaudiana extracts, via AMPK upregulation and antioxidant activities. Acta Sci. Pol. Technol. Aliment., 17(3), 289-297. http://dx.doi.org/10.17306/J.AFS.2018.0567

Mizutani, K., Tanaka, O. (2002). Use of Stevia rebaudiana sweeteners in Japan. In: A. D. Kinghorn, (Ed.), Stevia. The genus Stevia. Medicinal and Aromatic Plants - Industrial Profiles, vol. 19 (pp. 178-195). London - New York: Taylor and Francis.

Ohakawa, H., Oshishi, N., Yagi, K. (1979). Assay for lipid peroxidation in animal tissue by thiobarbituric acid reaction. Anal. Biochem., 75, 351-358. http://dx.doi. org/10.1016/0003-2697(79)90738-3

Ong, K. W., Hsu, A., Tan, B. K. (2012). Chlorogenic acid stimulates glucose transport in skeletal muscle via AMPK activation: A contributor to the beneficial effects of coffee on diabetes. PLOS ONE, 7(3), e32718. http:// dx.doi.org/10.1371/journal.pone.0032718

Petersen, K. F., Shulman, G. I. (2002). Pathogenesis of skeletal muscle insulin resistance in type 2 diabetes mellitus. Am. J Cardiol., 90(5A), 11G-18G. http://dx.doi. org/10.1016/S0002-9149(02)02554-7

Prata, C., Zambonin, L., Rizzo, B., Maraldi, T., Angeloni, C., Dalla Sega, F. V., ..., Hrelia, S. (2017). Glycosides from Stevia rebaudiana Bertoni possess insulin-mimetic and antioxidant activities in rat cardiac fibroblasts. Oxid. Med. Cell. Longev., 2017. ID 3724545. http://dx.doi. org/10.1155/2017/3724545

Rizzo, B., Zambonin, L., Angeloni, C., Leoncini, E., Dalla Sega, F. V., Prata, C., ..., Hrelia, S. (2013). Steviol glycosides modulate glucose transport in different cell types. Oxid. Med. Cell. Longev., 2013, ID 348169. http:// dx.doi.org/10.1155/2013/348169

Ruiz-Ruiz, J. C., Moguel-Ordonez, Y. B., Segura-Campos, M. R. (2017). Biological activity of Stevia rebaudiana Bertoni and their relationship to health. Crit. Rev. Food Sci. Nutr., 57(12), 2680-2690. http://dx.doi.org/10.1080 $/ 10408398.2015 .1072083$

Sahin, K., Tuzcu, M., Orhan, C., Gencoglu, H., Ulas, M., Atalay, M., ..., Komorowski, J. R. (2012). The effects of chromium picolinate and chromium histidinate administration on Nf- $\mathrm{\kappa B}$ and $\mathrm{Nrf} 2 / \mathrm{HO}-1$ pathway in the brain of diabetic rats. Biol. Trace Elem. Res., 150, 291-296. http://dx.doi.org/10.1007/s12011-012-9475-9

Shivanna, N., Naika, M., Khanum, F., Kaul, V. K. (2013). Antioxidant, anti-diabetic and renal protective properties of Stevia rebaudiana. J. Diab. Compl., 27(2), 103113. http://dx.doi.org/10.1016/j.jdiacomp.2012.10.001

Sies, H. (1997). Oxidative stress: oxidants and antioxidants. Exp. Physiol., 82, 291-295. http://dx.doi.org/10.1113/ expphysiol.1997.sp004024

Sigh, S., Garg, V., Yadav, D. (2013). Antihyperglucemic and antioxidative ability of Stevia rebaudiana (Bertoni) leaves in diabetes induced mice. Int. J. Pharm. Sci., 5(2), 297-302.

Thomas, C. C., Philipson, L. H. (2015). Update on diabetes classification. Med. Clin. North Am., 99, 1-16. https:// doi.org/10.1016/j.mcna.2014.08.015

Wasserman, D. H. (2009). Four grams of glucose. Am. J. Physiol., 296(1), E11-E21. http://dx.doi.org/10.1152/ ajpendo.90563.2008

Watson, R. T., Pessin, J. E. (2006). Bridging the GAP between insulin signaling and GLUT4 translocation. Trends Biochem. Sci., 31(4), 215-222. http://dx.doi. org/10.1016/j.tibs.2006.02.007

Wolff, S. P., Dean, R. T. (1987). Glucose autoxidation and protein modification. The potential role of 'autoxidative glycosylation' in diabetes. Biochem. J., 245(1), 243 250. http://dx.doi.org/10.1042/bj2450243

Xiang, Z., Ning, Z. (2008). Scavenging and antioxidant properties of compound derived from chlorogenic acid in South-China honeysuckle. LWT - Food Sci Technol., 41, 1189-1203. http://dx.doi.org/10.1016/j. lwt.2007.08.006 